\title{
Neonicotinoid insecticides disrupt predation on the eggs of turf-infesting scarab beetles
}

\author{
D.C. Peck* and D. Olmstead \\ Department of Entomology, New York State Agricultural \\ Experiment Station, Cornell University, 630 W. North St, Geneva, \\ NY 14456, USA
}

\begin{abstract}
Turfgrass applications of imidacloprid were previously shown to suppress the abundance of certain soil arthropods. To ascertain whether those impacts harbor functional consequences, the effect of neonicotinoids on Japanese beetle (Popillia japonica Newman) predation was examined in three experiments that measured removal of eggs implanted into non-irrigated field plots. A first experiment confirmed that a single imidacloprid application reduced the abundance of nontarget fauna and the rate of egg removal. A second experiment compared the impacts of imidacloprid with those of three other neonicotinoids, while a third measured the impact of imidacloprid when applied in July, August or September. Egg removal declined 28.3-76.1\% in imidacloprid-treated plots across all studies. Effects were detected as early as one week after treatment (WAT) and persisted as long as four WAT. The extent of suppression did not vary across month of application. Clothianidin, dinotefuran and thiamethoxam also suppressed egg removal, and the effects were similar among them and with imidacloprid. There was no discernible association between variation in rainfall and treatment effects, but this was not explicitly tested. Results support the hypotheses that a single neonicotinoid application can suppress predation on pest populations and that the effect does not vary with respect to active ingredient or season of application. Neonicotinoid application at the time of beetle oviposition puts intended effects (mortality of neonates) in conflict with unintended effects (disruption of egg predation). The conservation of predation on early life stages might buffer the reduced efficacy of late season applications that target more advanced instars. As application timing and post-application irrigation affect insecticide performance, they might also be manipulated to reduce nontarget effects.
\end{abstract}

Keywords: imidacloprid, nontarget effects, Popillia japonica, soil insect pests, turfgrass, white grubs

(Accepted 4 January 2010)

\section{Introduction}

Every pest management tactic potentially impacts the overall biological community and produces unintended or nontarget effects. As highlighted by recent scrutiny of Btinsecticidal crops and conventional insecticide applications

${ }^{*}$ Author for correspondence

Fax: +1-315-787-2326

E-mail: dp25@cornell.edu
(Dively, 2005; Marvier et al., 2007; Wolfenbarger et al., 2008), the salient question for guiding agricultural decision-making is how the unintended effects of a technology compare to 
those of the practices it can supplant. Another question is how relevant those nontarget effects actually are to agroecosystem health and sustainability. Minor reductions in the abundance of predators observed in Bt-cotton fields, for instance, were determined to have "little ecological meaning" for the natural regulation of pest populations (Naranjo, 2005a,b). These dimensions of nontarget assessment are probably relevant well beyond such high profile scenarios as geneticallymodified organisms and broad spectrum insecticides.

In managed turfgrass systems, carbamate and organophosphate insecticides have been shown, through diverse studies, to negatively impact the abundance of natural enemies (Cockfield \& Potter, 1983; Terry \& Potter, 1987; Vavrek \& Niemczyk, 1990), as well as their function in the regulation of pest populations (Cockfield \& Potter, 1983; Terry et al., 1993; Zenger \& Gibb, 2001; Rogers \& Potter, 2003). In the last decade, there has been a shift toward reliance on newer chemistries that feature lower vertebrate toxicity, reduced water solubility and more selective modes of action (Potter, 1998). Foremost among these are the neonicotinoids, including acetamiprid, clothianidin, dinotefuran, imidacloprid and thiamethoxam (Maienfisch et al., 2001; Tomizawa \& Casida, 2003; Wakita et al., 2003; Jeschke \& Nauen, 2008). While these still retain a relatively broad spectrum of insecticidal activity (Elbert et al., 1998), their systemic nature, like that of plant-induced toxins (e.g. $B t$-transgenic plants), is considered to have fewer nontarget effects due to reduced ecological exposure (Smith \& Krischik, 1999). It is, therefore, reasonable to expect that the magnitude of adverse effects on beneficial fauna like the natural enemies of pests might be diminished under control programs that favor these compounds. On the other hand, the relatively long-residual of neonicotinoids might result in increased environmental exposure to nontargets because of their persistence in the field.

Imidacloprid is probably the most widely used intervention product for turf-infesting white grubs (Coleoptera: Scarabaeidae) in the United States. Given the ideal application window at the time of oviposition, imidacloprid is applied preventively (Potter, 1998), meaning that application decisions are made before it is feasible to scout pest populations and to assess thresholds. Turf managers are, therefore, more likely to make preventive applications because there is no method to gauge infestation levels in advance. One ramification is that applications may be made against non-damaging populations; another is that repeated yearly applications might be promoted in risk-adverse settings, such as on golf course playing surfaces.

Studies, therefore, are needed to address whether there are discernible nontarget effects on beneficial arthropods from neonicotinoid insecticides, whether those impacts are relevant to turfgrass health, and, if so, how they might be mitigated. This approach is further justified by evidence that links imidacloprid to pollinator declines (Chauzat et al., 2006; Halm et al., 2006; Abbott et al., 2008) and by the extensive areas managed for production and amenity turf. There are an estimated $200,000 \mathrm{~km}^{2}$ of cultivated turfgrass in the US, providing a broad range of aesthetic, economic, recreational and environmental services (Beard \& Green, 1994; NTF, 2003). In addition to production grass seed and sod farms, turf systems include residential home lawns, golf courses, athletic fields, parks and other public areas. In New York State, for instance, turfgrass covers $13,800 \mathrm{~km}^{2}$ and contributes $\$ 5.1$ billion annually to the state's economy (NASS, 2004). Across these systems, white grubs are the most widespread and damaging insect pest complex, and their management would benefit from more informed decision-making as to the selection and application of control interventions.

In previous studies with white grub control options like trichlorfon, halofenozide and entomopathogenic nematodes, only imidacloprid harbored discernible nontarget impacts on the abundance of soil-active invertebrates in turfgrass (Peck, 2009a). Repeated preventive applications reduced populations of certain nontarget taxa, including Coleoptera, Collembola, Hemiptera and Thysanoptera, the effects of which persisted over all six years of applications (Peck, 2009b). Population reductions were expressed in the soilactive fauna recovered through Tullgren funnel extractions of soil cores, but not in the surface-active fauna captured from pitfall traps. Among the affected taxa are beneficials that probably play a role in stabilizing the turfgrass ecosystem through nutrient cycling and the natural regulation of pest populations. In turfgrass, the activities of decomposers such as earthworms and springtails contribute to thatch decomposition, while the activities of generalist natural enemies, such as ants, ground beetles and spiders, contribute to suppression of pest outbreaks (Potter, 1993, 1994). The extent to which selective pest management tactics can protect the services of these groups is key to maintaining healthy turf. Although imidacloprid is implicated in suppressing the populations of these potential beneficial soildwelling organisms, it is unknown if the magnitude of that effect has any relevance for their function in ecological processes, i.e. whether the amount of beneficial population reduction induced by imidacloprid will significantly impact pest management. Balanced with the positive attributes of a preventive imidacloprid regime in limiting the impact of white grub outbreaks, do we need to care that beetles and other groups suffer collateral damage?

This study examines the impact of single applications of neonicotinoid insecticides on the regulation of pest populations by predators. The objective was to detect and measure the magnitude and persistence of neonicotinoid impacts on the removal rates of Japanese beetle (Popillia japonica Newman) eggs. The egg was chosen because it is a known prey item for generalist natural enemies, it has been previously used to gauge the impacts of other insecticides, and it is present when preventive applications are made. The study was conducted as a series of three experiments. In a first experiment, data were obtained that confirmed the potential of a single application of imidacloprid to suppress the abundance of nontarget fauna and the rate of egg removal. A second experiment was conducted to compare the impact of four neonicotinoid insecticides on egg removal. Finally, a third experiment was conducted to measure changes in egg removal when imidacloprid was applied to target white grubs at three different times over the season. The working hypothesis was that a single application of neonicotinoid insecticide can lead to lower rates of egg predation and that the effect is temporary and does not vary with respect to active ingredient or month of application.

\section{Methods \\ Study site}

The experiments were conducted at the Crittenden North research farm at Cornell University's New York State 
Table 1. Environmental conditions at time of application and precipitation post-application.

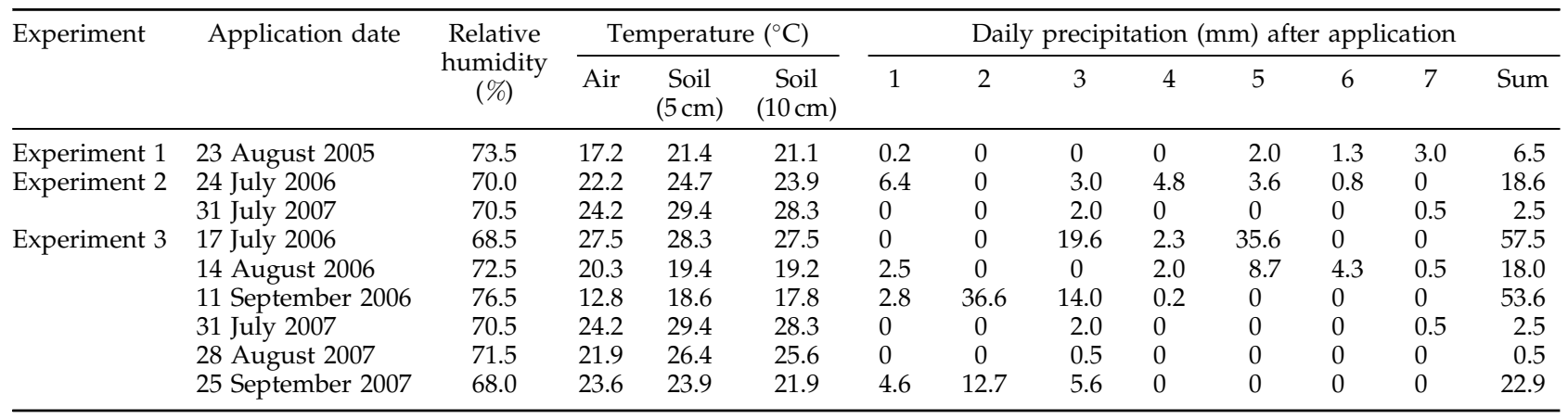

Agricultural Experiment Station, Geneva, NY. Study plots were situated on a 1.3-ha site managed to simulate a low maintenance home lawn. The experimental area received no irrigation, fertilization, pesticides or overseeding since its conversion in 1997 from an orchard fallow. Maintenance involved weekly mowing (cutting height $10.4 \mathrm{~cm}$ ) with clippings left on the surface. Starting in 2006, there was an autumn aeration using a tractor-pulled core aerator. A single

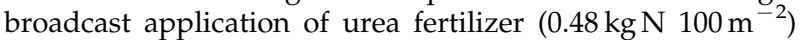
was made in June 2007. Turf composition was fine fescue $(38.0 \%)$, perennial ryegrass $(22.7 \%)$, weedy grass species $(0.8 \%)$ and broadleaf weeds $(37.9 \%)$. Soil was silty clay loam ( $12.5 \%$ sand, $55.0 \%$ silt, $32.5 \%$ clay) with $5.7 \%$ organic matter and $\mathrm{pH}$ 6.5. All experimental plots were $10 \times 10 \mathrm{~m}$, separated from one another by a $10-\mathrm{m}$ untreated buffer.

\section{Treatment applications}

Most insecticide treatments were applied in liquid formulation using a pressurized $\mathrm{CO}_{2}$ sprayer system ( $\mathrm{R}$ and D Sprayers, Opelousas, LA). Applications were made at $30 \mathrm{psi}$, using a 1.2-m boom fitted with four flat fan nozzles (Teejet $($ $)$ 8002VS, TeeJet Technologies, Wheaton, IL) for a final coverage width of $1.5 \mathrm{~m}$. Application volume was standardized to 1.2 liters $100 \mathrm{~m}^{-2}$. Rate of application matched the standard labeled rates for turfgrass application, or, in the case of dinotefuran (not labeled for use on turf), the maximum labeled rate for ornamental plants. Four neonicotinoid insecticides were included in these studies based on the following products and rates: clothianidin (Arena 50 WDG, $0.21 \mathrm{~kg}^{\mathrm{AI}} \mathrm{ha}^{-1}$, Valent, Richardson, TX), dinotefuran (Safari $20 \mathrm{SG}, 0.59 \mathrm{~kg} \mathrm{AI} \mathrm{ha}^{-1}$, Valent), imidacloprid (Merit $2 \mathrm{~F}, 0.44 \mathrm{~kg} \mathrm{AI} \mathrm{ha}^{-1}$, Bayer Environmental Science, Montvale, NJ) and thiamethoxam (Meridian $25 \mathrm{WG}, 0.31 \mathrm{~kg} \mathrm{AI} \mathrm{ha}^{-1}$, Syngenta, Wilmington, DE). Nothing was applied to the untreated check plots. Experiment 1 (see below) was an exception because imidacloprid was applied in a granular formulation (Merit $0.2 \mathrm{G}, 0.44 \mathrm{~kg} \mathrm{AI} \mathrm{ha}^{-1}$, Bayer CropScience, Research Triangle Park, NC) with a drop spreader (Model \#D, Gandy, Owatanna, MN).

Post-application irrigation is part of the strategy to improve how insecticides target white grubs that reside at the soil/thatch interface. This practice may not be very common, however, given the lack of explicit information on product labels and the prevalence of non-irrigated turf systems. Therefore, our reliance on natural precipitation represents a common - but not ideal - application practice for neonicotinoids in white grub control. In order to fully document application conditions, we recorded daily precipitation over a one-week period after each date of application along with other environmental parameters at the time of application (table 1). Overall, $\geq 2.0 \mathrm{~mm}$ of precipitation occurred within three days after each application date, with the exception of experiment 1 , where it was delayed until the fifth day.

\section{Japanese beetle egg predation}

As one measure of natural predation rates, protocols were adapted from Terry et al. (1993) to gather data on Japanese beetle egg removal. Newly laid, viable eggs were obtained from Japanese beetle adults that were collected in the vicinity using standard vane traps (Tanglefoot, Grand Rapids, MI) fitted with pheromone/floral lures (Spectracide Bag-a-bug floral lures, Spectrum Brands, Atlanta, GA). Beetles were provisioned with fresh wild grape leaves, Vitis vinifera L., and were held in wood-framed screen cages $(0.5 \times 0.5 \times 0.5 \mathrm{~m})$ with sandy-loam soil for oviposition. Newly laid eggs were separated from the soil using a coarse sieve and/or flotation in a $3 \mathrm{M}(17.4 \% \mathrm{w} / \mathrm{v})$ solution of $\mathrm{NaCl}$.

Predation trays were designed that would allow eggs to be implanted as naturally as possible into the soil profile of experimental field plots. Trays were constructed from the bottom of 50-mm diameter Petri dishes. A 45-mm diameter portion of the bottom was replaced with aluminum window screen (mesh size $1.13 \times 1.30 \mathrm{~mm}$ ) held in place with silicone caulk. Lined with a $42.5-\mathrm{mm}$ diameter piece of filter paper, the resulting unit provided a stable surface for the placement of eggs, air and water exchange between the soil and eggs through the filter paper- and screen-lined bottom, and free access to soil-inhabiting arthropods through the open top. To measure egg removal rates, ten eggs were placed in each tray after moistening the filter paper with distilled water to promote adhesion. To implant a tray into the soil profile, a 5-cm diameter core was removed using a tubular turfplugger (Turf Tec, Tallahassee, FL) set to a depth of $5 \mathrm{~cm}$. One tray was placed flat onto the bottom of the hole left by the soil core, and then the core was gently replaced back into the hole without crushing the eggs or disrupting the tray. Five $(2005)$ or six $(2006,2007)$ trays were implanted per experimental plot. In 2005, the insertion sites were approximately plot center and $2 \mathrm{~m}$ from each corner on the diagonal axes. In 2006 and 2007, however, the trays were placed at locations that were selected at random. After exposure for 
two days, trays were recovered to count the number of eggs remaining.

\section{Impact on arthropods}

To measure the activity-density of surface-active arthropods, five permanent pitfall traps were established in each plot. One trap was located in the center of the plot, the others one meter from each corner on the diagonal axes. Traps consisted of $1.1-1$ plastic cups $(11 \mathrm{~cm}$ top diameter, $15 \mathrm{~cm}$ deep) buried flush with the surface in holes opened up by removing a 10.4-cm diameter core with a golf course cup cutter. Trapping was conducted over two-day intervals. A removable $0.54-1$ cup ( $11 \mathrm{~cm}$ top diameter, $7.5 \mathrm{~cm}$ deep) was placed inside the first buried cup to serve as the capture cup. The removable capture cup was filled with $\approx 3 \mathrm{~cm}$ of propylene glycol to retain and preserve arthropod captures. Traps were covered with tight fitting plastic lids during the intervals between sampling. The content of each trap was transferred to $70 \%$ ethyl alcohol for storage until taxonomic assessment.

To measure the density of soil-active arthropods, a series of 15 soil cores was extracted haphazardly from the surface of each plot with a 5-cm diameter turf plugger set to a depth of $5 \mathrm{~cm}$. A $1-\mathrm{m}$ border was excluded. Cores from each plot were grouped together, grass side down, in modified Tullgren funnels, each fitted with a $40 \mathrm{~W}$ light bulb. Samples were held three days under those conditions for extraction of invertebrates into $70 \%$ ethyl alcohol.

Invertebrates captured from pitfall traps and extracted from soil cores were sorted and enumerated. All were identified to class, hexapods to order, and some to family or other taxonomic grouping.

\section{Short-term effects of imidacloprid on egg removal and nontarget arthropods (experiment 1)}

A first experiment was conducted in 2005 to confirm protocols and substantiate the idea that a single application could impact egg removal rates. While no attempt was made to establish which taxa might be involved with egg removal, a suppressive effect of imidacloprid on nontarget taxa needed verification. Therefore, we also measured impacts on the incidence of soil- and surface-active fauna.

Treatments were applied 23 August 2005 to experimental plots arranged in a randomized complete block design with six repetitions of untreated and imidacloprid-treated plots. Egg predation, soil-active predators and surface-active predators were assessed at ten and 20 days after treatment (DAT). The egg predation protocols diverged from later studies in that trays were lined with a 1-mm layer of soil rather than filter paper. Furthermore, to deploy trays, a $10.4-\mathrm{cm}$ diameter soil was removed to a depth of $15 \mathrm{~cm}$; a horizontal slit was made in the side, just below the thatch layer; the tray was inserted; and the core was replaced. Egg removal rates were analyzed with analysis of variance (ANOVA) to test for an effect of treatment, and assessed with a type I error rate of $5 \%(P=0.05)$. Given departures from the assumption of normality, data on the abundance of soil-active arthropods and the abundance-activity of surfaceactive arthropods were analyzed with the nonparametric Wilcoxon rank-sum test. Given an a priori expectation of declines in the abundance of taxa in treated plots (Peck, $2009 a, b)$, a type I error rate of $10 \%(P=0.10)$ was used to assess all treatment-related fixed effects for the soil core captures. The two sampling dates were analyzed separately. In order to measure loss of eggs due to experimental manipulation, a series of ten additional trays were implanted just outside the experimental plots, left in place for $5 \mathrm{~min}$, and then recovered. For this study and the following, statistical calculations were conducted with JMP Statistical Discovery software (SAS Institute, 2003) and means were reported with their standard error.

\section{Comparative impacts of four neonicotinoids (experiment 2)}

A second experiment was conducted in 2006 and 2007 to compare the impacts of clothianidin, dinotefuran, imidacloprid and thiamethoxam on egg removal rates. Field work was completed over a one-month interval in 2006 and repeated again in 2007 on a different set of plots. Application dates were 24 July 2006 and 31 July 2007. Egg predation was assessed at 1, 8, 15 and 22 DAT in each year, hereafter referred to as one, two, three and four weeks after treatment (WAT). Arthropods were not sampled in this experiment. Thiamethoxam was not available for inclusion at one WAT in 2006.

This study was conducted each year as a completely randomized design with six repetitions, and analyzed with ANOVA to test for an effect of neonicotinoid treatment with respect to WAT. Following a significant effect of WAT, differences among treatments were explored for each WAT using the least significant difference (LSD) means separation procedure. Analyses were assessed with a type I error rate of $5 \%(P=0.05)$. Given the magnitude of differences in egg removal rates between years, data were analyzed separately for each year.

\section{Seasonal variation in the impact of imidacloprid (experiment 3)}

A third experiment was conducted in 2006 and 2007 to compare the impact of imidacloprid when the application was made at different times in the season. While application timing is recommended for the period of scarab beetle oviposition, field efficacy has been demonstrated as early as late April (e.g. Heller \& Kline, 2007) and as late as early September (e.g. Heller \& Kline, 2005; Swier \& Rollins, 2006). Fieldwork was conducted over a three-month interval in 2006 and repeated again in 2007. Applications were made in July, August and September, corresponding to 17 July, 14 August and 11 September in 2006, and 31 July, 28 August and 25 September in 2007. Each trial was conducted on a different set of plots. Egg removal rates were assessed at one, two, three and four WAT. Arthropods were not sampled in this experiment. Each month of application was arranged and analyzed in a randomized complete block design with six repetitions. Data were analyzed separately for each year to test for an effect of imidacloprid treatment with respect to WAT and month of application. The overall mixed model ANOVA included block as a random effect, with treatment, WAT, month and their interactions as fixed effects. Following a significant effect of treatment, further differences among fixed effects were explored using multiple means comparisons. Based on results from 2005 (experiment 1), a type I error rate of $10 \%(P=0.10)$ was used given an a priori expectation of declines in egg removal rates. 
Table 2. Number of captures from pitfall traps in untreated and imidacloprid plots at ten and $20 \mathrm{~d}$ after treatment (DAT).

\begin{tabular}{|c|c|c|c|c|c|c|}
\hline Class: Order & Family/Other: Subgroup & DAT & $\begin{array}{c}\text { Total } \\
\text { individuals }\end{array}$ & \multicolumn{2}{|c|}{ Mean \pm SE no. per sample ${ }^{1}$} & $\begin{array}{l}\text { Wilcoxon } \\
\text { Rank Sum } \\
\text { Prob }>|Z|^{2}\end{array}$ \\
\hline \multicolumn{7}{|l|}{ Arachnida: } \\
\hline \multirow{3}{*}{ Acari } & & 20 & 1 & $0 \pm 0$ & $0.2 \pm 0.2$ & 0.218 \\
\hline & Other & 10 & 37 & $2.8 \pm 1.4$ & $3.3 \pm 1.0$ & 0.574 \\
\hline & & 20 & 6 & $0.2 \pm 0.2$ & $0.8 \pm 0.4$ & 0.119 \\
\hline \multirow{2}{*}{ Araneae } & Other & 10 & 97 & $7.0 \pm 1.3$ & $9.2 \pm 1.0$ & $0.004^{* * *}$ \\
\hline & & 20 & 33 & $2.3 \pm 0.8$ & $3.2 \pm 1.1$ & $0.067^{*}$ \\
\hline \multirow[t]{2}{*}{ Opiliones } & & 10 & 49 & $4.0 \pm 3.3$ & $4.2 \pm 1.5$ & 0.873 \\
\hline & & 20 & 17 & $2.3 \pm 0.8$ & $0.7 \pm 0.3$ & 0.732 \\
\hline \multicolumn{7}{|l|}{ Hexapoda: } \\
\hline Coleoptera & Carabidae & 10 & 36 & $2.0 \pm 0.6$ & $4.0 \pm 1.0$ & $0.006^{* * *}$ \\
\hline \multirow[t]{2}{*}{ Orthoptera } & & 10 & 138 & $12.8 \pm 1.8$ & $10.2 \pm 3.6$ & $0.092^{*}$ \\
\hline & & 20 & 52 & $5.3 \pm 2.1$ & $3.3 \pm 1.1$ & $0.036^{* *}$ \\
\hline \multirow[t]{4}{*}{ Hymenoptera } & Formicidae: Myrmicinae & 10 & 145 & $10.5 \pm 2.4$ & $13.7 \pm 5.6$ & 0.574 \\
\hline & & 20 & 42 & $1.5 \pm 0.2$ & $5.5 \pm 2.0$ & $0.030^{* *}$ \\
\hline & Formicidae: Other & 10 & 16 & $1.8 \pm 0.5$ & $0.8 \pm 0.3$ & $0.011^{* *}$ \\
\hline & & 20 & 6 & $0.3 \pm 0.3$ & $0.7 \pm 0.5$ & $0.069^{*}$ \\
\hline \multicolumn{7}{|l|}{ Malacostraca: } \\
\hline \multirow[t]{4}{*}{ Isopoda } & Armadillidiidae (pillbugs) & 10 & 24 & $2.2 \pm 0.5$ & $1.8 \pm 0.9$ & 0.628 \\
\hline & & 20 & 4 & $0.5 \pm 0.3$ & $0.2 \pm 0.2$ & 0.391 \\
\hline & Porcellionidae (sowbugs) & 10 & 408 & $49.0 \pm 12.2$ & $19.0 \pm 5.6$ & $0.005^{* * *}$ \\
\hline & & 20 & 66 & $8.2 \pm 3.1$ & $2.8 \pm 1.1$ & 0.147 \\
\hline
\end{tabular}

${ }_{1}$ Each sample consisted of captures from five 11-cm diameter pitfall traps per plot, opened for two days.

2 Significant differences are highlighted with asterisks at $P \leq 0.10\left(^{*}\right), P \leq 0.05\left(^{* *}\right)$ and $P \leq 0.01\left(^{* * *}\right)$.

3 Suborder classification.

\section{Results}

\section{Short-term effects of imidacloprid on nontarget arthropods (experiment 1)}

From the pitfall traps, a total of 1448 individuals were captured, representing seven hexapod orders and three other arthropod classes. A partial listing of the numerically dominant taxa is provided in table 2. Several other taxonomic groups were detected but not included in the statistical analysis because of low numbers $(n<20$ pooled across both DAT). These included the hexapod orders Coleoptera (Scarabaeidae, Staphylinidae), Diptera, Hemiptera, Hymenoptera and Lepidoptera, plus the classes Diplopoda and Gastropoda (snails, slugs).

There was a significant effect of treatment on the number of total pitfall captures at ten DAT $(S=21, Z=-2.81$, $P=0.0049)$ and $20 \mathrm{DAT}(\mathrm{S}=28, \mathrm{Z}=-1.69, P=0.092)$. At ten DAT, the mean number of total captures was $30.5 \%$ lower in the imidacloprid plots $(78.2 \pm 10.40)$ compared to the untreated plots $(112.5 \pm 14.0)$. At 20 DAT, the mean number of total captures was $21.0 \%$ lower in the imidacloprid plots $(22.3 \pm 2.0)$ compared to the untreated plots $(28.3 \pm 5.0)$.

Among the individual taxa, at ten DAT, there was a significant reduction in arthropod abundance in imidacloprid plots compared to the untreated plots for captures of Symphypleona (95.3\% reduction), Entomobryomorpha $(83.3 \%)$, Porcellionidae $(61.2 \%)$, non-myrmicine Formicidae
(55.6\%) and Orthoptera (20.3\%) (table 2). In contrast, captures were significantly higher in the imidacloprid plots for non-lycosid Araneae and Carabidae. At 20 DAT, there was a significant reduction in arthropod abundance in imidacloprid plots for captures of Carabidae (71.4\%) and Orthoptera $(37.7 \%)$ but a significant increase in captures of non-lycosid Araneae, non-myrmicine Formicidae and Myrmicinae.

From the soil cores, a total of 8331 individuals were extracted, representing nine hexapod orders and five other arthropod classes. A partial listing of the numerically dominant taxa is provided in table 3. Several other taxonomic groups were detected but not included in the statistical analysis because of low numbers $(n<20$ pooled across both DAT). These included the hexapod orders Coleoptera (Bruchidae, Chrysomelidae, Curculionidae, Elateridae, Lathridiidae, Nitidulidae), Collembola (Symphypleona), Lepidoptera, Protura and Psocoptera, plus the classes Chilopoda, Diplopoda, Gastropoda (snails), Malacostraca (Isopoda), Oligochaeta (Enchytraeidae, Lumbricidae) and Symphyla. Considering only the untreated check, the extraction rates for ten and 20 DAT, respectively, were 14,811 and 11,827 individuals $\mathrm{m}^{-2}$ of turf and associated topsoil.

As with pitfall traps, there was a significant effect of imidacloprid on the mean number of total captures at ten DAT $(S=21, Z=-2.80, P=0.0051)$, but an effect was not apparent at $20 \mathrm{DAT}(S=36, Z=-0.40, P=0.689)$. At ten 
Table 3. Number of captures extracted from soil cores in untreated and imidacloprid plots at ten and $20 \mathrm{~d}$ after treatment (DAT).

\begin{tabular}{|c|c|c|c|c|c|c|}
\hline Class: Order & Family/Other: Subgroup & DAT & Total individuals & \multicolumn{2}{|c|}{ Mean \pm SE no. per sample ${ }^{1}$} & $\begin{array}{l}\text { Wilcoxon } \\
\text { Rank Sum } \\
\text { Prob }>|Z|^{2}\end{array}$ \\
\hline \multicolumn{7}{|l|}{ Arachnida: } \\
\hline \multirow{3}{*}{ Acari } & & 20 & 1,284 & $76.2 \pm 14.8$ & $137.8 \pm 38.1$ & $0.020 * *$ \\
\hline & Other & 10 & 901 & $72.5 \pm 13.4$ & $77.7 \pm 27.0$ & 0.575 \\
\hline & & 20 & 940 & $64.7 \pm 21.2$ & $92.0 \pm 23.6$ & 0.298 \\
\hline \multicolumn{7}{|l|}{ Hexapoda: } \\
\hline \multirow[t]{5}{*}{ Coleoptera } & Larvae & 10 & 13 & $1.3 \pm 0.8$ & $0.8 \pm 0.4$ & 0.288 \\
\hline & & 20 & 15 & $1.2 \pm 0.5$ & $1.3 \pm 0.6$ & 0.935 \\
\hline & Carabidae: Adults & 10 & 43 & $3.3 \pm 1.6$ & $3.8 \pm 1.3$ & 0.936 \\
\hline & & 20 & 22 & $1.8 \pm 1.3$ & $1.8 \pm 1.2$ & 0.732 \\
\hline & Staphylinidae: Adults & 10 & 10 & $1.0 \pm 0.5$ & $0.7 \pm 0.5$ & 0.742 \\
\hline \multirow{8}{*}{ Collembola } & Entomobryomorpha: ${ }^{3}$ & 10 & 67 & $10.8 \pm 3.5$ & $0.3 \pm 0.2$ & $0.005^{* * *}$ \\
\hline & Proisotoma & 20 & 19 & $2.8 \pm 1.3$ & $0.3 \pm 0.3$ & $0.012^{* *}$ \\
\hline & Entomobryomorpha: ${ }^{3}$ & 10 & 112 & $11.0 \pm 2.6$ & $7.7 \pm 2.3$ & $0.051^{*}$ \\
\hline & Pseudosinella & 20 & 66 & $5.3 \pm 2.8$ & $5.7 \pm 2.1$ & 0.688 \\
\hline & Poduromorpha: ${ }^{3}$ & 10 & 72 & $9.2 \pm 2.8$ & $2.8 \pm 0.7$ & $0.020^{* *}$ \\
\hline & Onychiurus & 20 & 0 & $0 \pm 0$ & $0 \pm 0$ & - \\
\hline & Symphypleona $^{3}$ & 10 & 7 & $1.0 \pm 0.8$ & $0.2 \pm 0.2$ & $0.070^{*}$ \\
\hline & & 20 & 6 & $0.8+0.6$ & $0.2+0.2$ & 0.391 \\
\hline \multirow[t]{2}{*}{ Diptera } & Larvae & 10 & 114 & $12.3 \pm 6.2$ & $6.7 \pm 3.1$ & 0.109 \\
\hline & & 20 & 14 & $1.8 \pm 0.7$ & $0.5 \pm 0.5$ & 0.104 \\
\hline \multirow[t]{3}{*}{ Hemiptera } & Total & 10 & 831 & $98.0 \pm 28.2$ & $40.5 \pm 10.5$ & $0.013^{* *}$ \\
\hline & & 20 & 688 & $58.0 \pm 18.8$ & $56.7 \pm 27.6$ & 0.810 \\
\hline & Auchenorrhyncha: ${ }^{3}$ & 10 & 54 & $5.7 \pm 4.9$ & $3.3 \pm 2.0$ & 0.935 \\
\hline \multirow{9}{*}{ Hymenoptera } & & 20 & 814 & $104.0 \pm 41.3$ & $31.7 \pm 8.6$ & $0.045^{* *}$ \\
\hline & Formicidae: & 10 & 23 & $3.7 \pm 3.7$ & $0.2 \pm 0.2$ & 0.218 \\
\hline & Dolichoderinae adults & 20 & 0 & $0 \pm 0$ & $0 \pm 0$ & - \\
\hline & Formicidae: Formicinae adults & 10 & 28 & $3.8 \pm 2.4$ & $0.8 \pm 0.8$ & $0.026^{* *}$ \\
\hline & Lasius alienus/L. Neoniger & 20 & 32 & $2.3 \pm 1.0$ & $3.0 \pm 1.2$ & 0.748 \\
\hline & Formicidae: Myrmicinae adults & 10 & 597 & $75.5 \pm 29.0$ & $24.0 \pm 18.0$ & 0.128 \\
\hline & Solenopsis molesta & 20 & 695 & $96.3 \pm 41.3$ & $19.5 \pm 6.0$ & $0.045^{* *}$ \\
\hline & Formicidae: & 10 & 69 & $4.2 \pm 0.8$ & $7.3 \pm 5.2$ & 0.689 \\
\hline & Ponerinae adults & 20 & 75 & $4.5 \pm 1.5$ & $8.0 \pm 3.0$ & 0.375 \\
\hline \multirow[t]{2}{*}{ Thysanoptera } & & 10 & 48 & $5.2 \pm 1.6$ & $2.8 \pm 0.6$ & $0.077^{*}$ \\
\hline & & 20 & 60 & $5.5 \pm 1.8$ & $4.5 \pm 1.8$ & 0.422 \\
\hline
\end{tabular}

${ }^{1}$ Each sample consisted of Tullgren funnel extractions from 15 soil cores (diameter and depth $5 \mathrm{~cm}$ ) per plot.

2 Significant differences are highlighted with asterisks at $P \leq 0.10\left(^{*}\right), P \leq 0.05\left(^{* *}\right)$ and $P \leq 0.01\left(^{* * *}\right)$.

3 Suborder classification.

DAT, the number of total captures was $43.4 \%$ lower in the imidacloprid plots $(246.7 \pm 35.9)$ compared to the untreated plots $(436.0 \pm 52.0)$. A difference was no longer detected at 20 DAT, when captures were nearly identical between treatments $(357.7 \pm 96.8$ imidacloprid, $348.2 \pm 66.8$ untreated).

Among the individual taxa, at ten DAT, there was a significant reduction in arthropod abundance in imidacloprid plots compared to the untreated plots for Proisotoma
(97.2\%), Lasius (78.9\%), Onychiurus (69.6\%), Collembola (63.8\%), Formicidae adults (62.3\%), Pseudococcoidea $(60.4 \%)$, total Hemiptera (58.7\%), Oribatidae $(41.7 \%)$ and Pseudosinella (30.0\%). In contrast, captures of Araneae were significantly higher in the imidacloprid plots. At 20 DAT, there was a significant reduction in imidacloprid plots for Solenopsis molesta (79.8\%), Aphididae (70.0\%), Formicidae adults (69.5\%) and Proisotoma $(45.0 \%)$ but a significant increase for Oribatidae. 

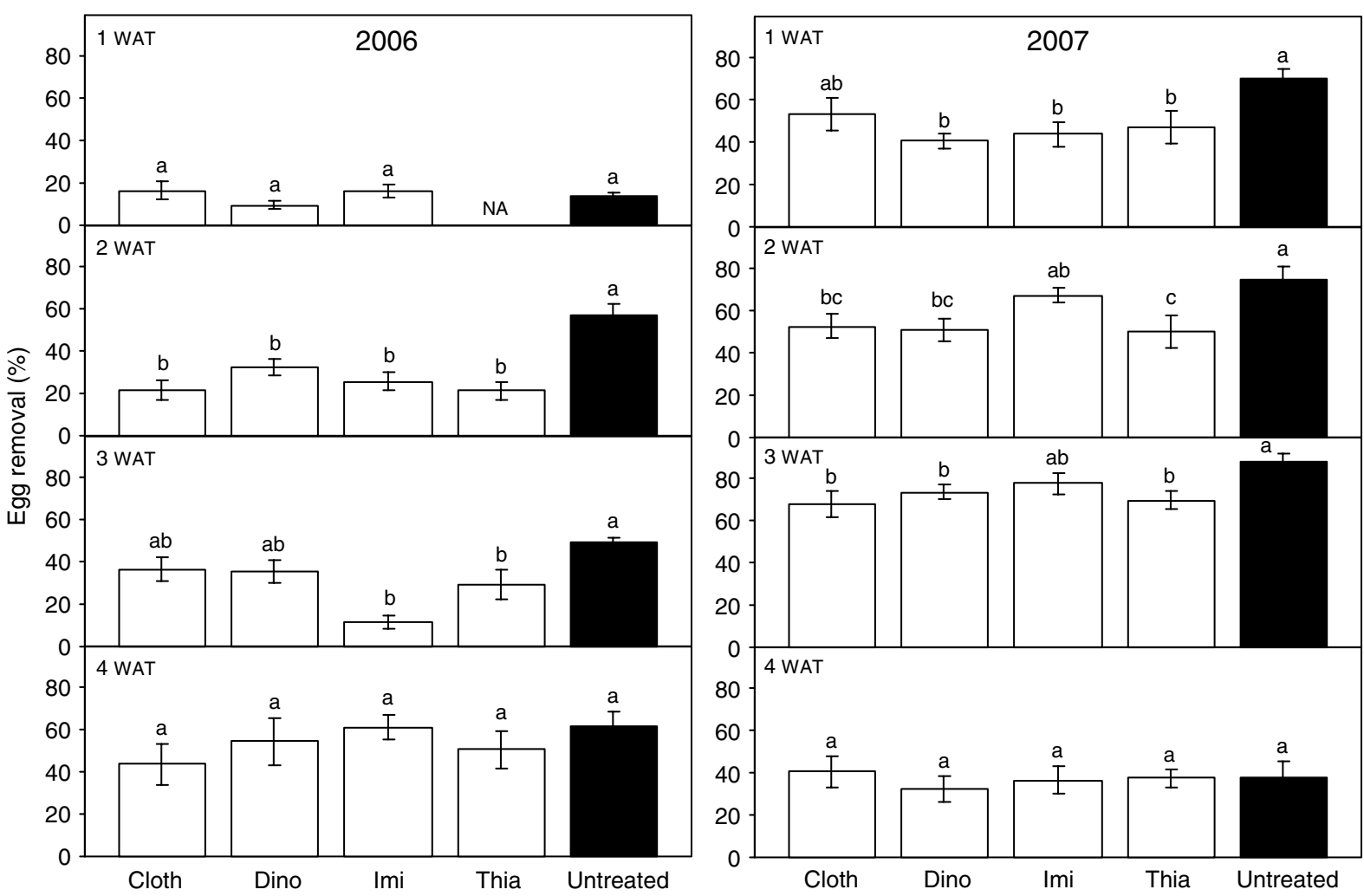

Fig. 1. Mean $( \pm S E)$ removal of Japanese beetle eggs assessed in weeks one, two, three and four after treatment (WAT) in untreated plots and those treated with clothianidin (Cloth), dinotefuran (Dino), imidacloprid (Imi) and thiamethoxam (Thia) in 2006 and 2007. Thiamethoxam was not evaluated at one WAT in 2006. For each time, columns with different letters are significantly different (leastsquares means comparisons, $P \leq 0.05$ ).

\section{Short-term effects of imidacloprid on Japanese beetle egg removal (experiment 1)}

For the two sampling dates, mean two-day egg removal rates in the untreated check were $62.7 \pm 8.2 \%$ at ten DAT and $93.0 \pm 4.4 \%$ at $20 \mathrm{DAT}$, or $77.8 \%$ when averaged across both DAT. While it was impossible to confirm that each egg was lost due to the action of predators, the loss due to experimental manipulation was close to negligible. In the test of implantation procedures, $99 \%$ of eggs were recovered.

There was a significant effect of imidacloprid on egg removal at ten DAT $(\mathrm{F}=8.3 ; \mathrm{df}=1,4 ; P=0.045)$ but not 20 DAT $(\mathrm{F}=0.0076 ; \mathrm{df}=1,5 ; P=0.934)$. At ten DAT, the mean removal rate in the untreated plots $(62.7 \pm 8.2 \%)$ was almost twice that of the imidacloprid plots $(32.8 \pm 5.2 \%)$. A difference was no longer detected at 20 DAT when the mean removal rates were nearly identical between treatments $(93.0 \pm 4.4 \%$ untreated, $92.3 \pm 3.8 \%$ imidacloprid $)$.

\section{Comparative impacts of four neonicotinoids (experiment 2)}

Egg removal rates were significantly lower in 2006 than in $2007(\mathrm{~F}=14.9 ; \mathrm{df}=1,46 ; P=0.0003)$. Averaged across the four sampling dates, mean two-day egg removal rate in the untreated check was $41.3 \pm 4.8 \%$ in 2006 and $67.2 \pm 4.7 \%$ in 2007. In 2006 (fig. 1), there was a significant effect of week $(\mathrm{F}=29.71 ; \mathrm{df}=3,76 ; P<0.0001)$, treatment $(\mathrm{F}=5.05$; $\mathrm{df}=3,76 ; P=0.003)$, and week $\times$ treatment $(\mathrm{F}=2.25 ; \mathrm{df}=9,76$;
$P=0.027)$. There was no difference in egg removal across the experimental plots at one WAT $(\mathrm{F}=1.23 ; \mathrm{df}=3,20 ; P=0.326)$. By two WAT, however, egg removal was significantly lower in all insecticide plots $(\mathrm{F}=3.88 ; \mathrm{df}=4,23 ; P=0.015)$. Clothianidin, dinotefuran, imidacloprid and thiamethoxam treatments reduced egg removal by $62.0,43.5,55.2$ and $63.0 \%$ compared to the untreated plots. A significant egg removal effect remained at three WAT $(\mathrm{F}=5.73 ; \mathrm{df}=4,23 ; P=0.0024)$, but it was only expressed in imidacloprid and thiamethoxam plots, which reduced removal by 76.1 and $40.4 \%$, respectively. By four WAT, there was no longer any effect of treatment on egg removal $(\mathrm{F}=0.76 ; \mathrm{df}=4,25 ; P=0.56)$. Based on the difference between the highest and lowest egg removal rates, variation among insecticides was only 7.0, $11.1,24.4$ and $17.2 \%$ at one, two, three and four WAT.

In 2007 (fig. 2), there was a significant effect of week $(\mathrm{F}=37.72 ; \mathrm{df}=3,100 ; P<0.0001)$ and treatment $(\mathrm{F}=6.05$; $\mathrm{df}=4,100 ; P=0.0002)$, but not week $\times$ treatment $(\mathrm{F}=1.24$; $\mathrm{df}=12,100 ; P=0.27)$. A treatment effect on egg removal was already expressed at one WAT $(\mathrm{F}=3.57 ; \mathrm{df}=4,25 ; P=0.020)$. Dinotefuran, imidacloprid and thiamethoxam reduced removal by $41.8,37.4$ and $43.6 \%$, compared to the untreated plots. At two WAT $(\mathrm{F}=3.52 ; \mathrm{df}=4,25 ; P=0.021)$ and three WAT $(\mathrm{F}=2.91 ; \mathrm{df}=4,25 ; P=0.042)$, respectively, clothianidin, dinotefuran and thiamethoxam reduced egg removal by 29.6, 31.5, 36.2\% and 22.9, 16.5, 44.5\%. There was an effect of imidacloprid at one WAT, but not at two or three WAT. As in 2006, by four WAT, there was no egg removal effect 


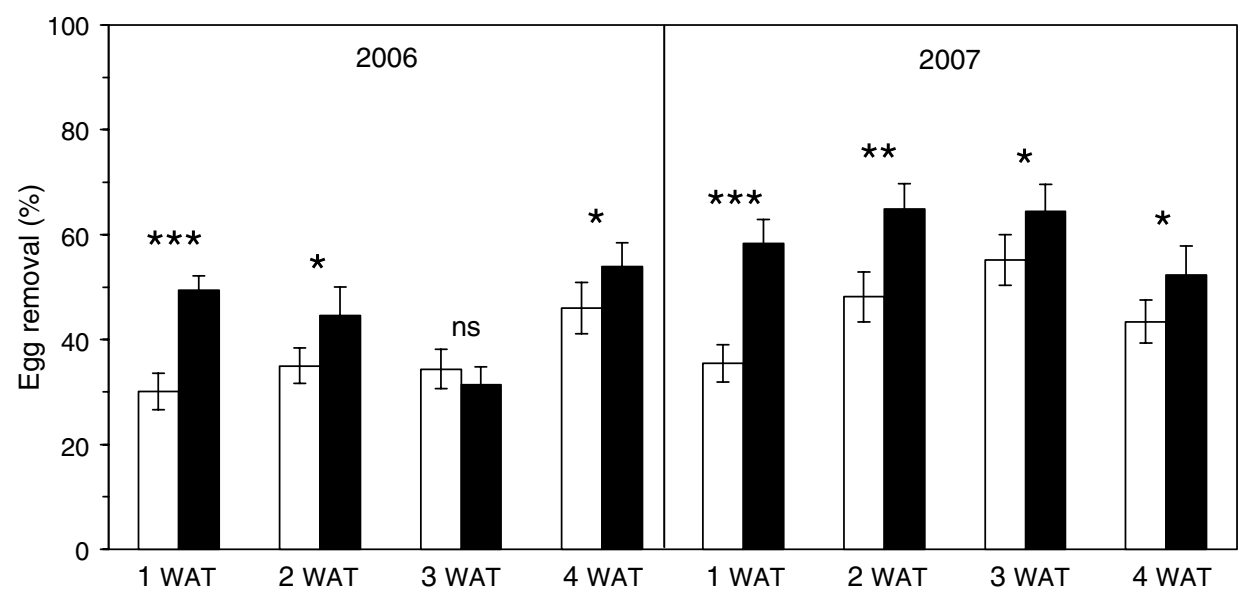

Fig. 2. Mean $( \pm S E)$ removal of Japanese beetle eggs, with respect to year, week after treatment (WAT: $1-4)$ and treatment, pooled across three application dates (July, August, September). White bars are imidacloprid treated plots and black bars are untreated plots. For each WAT, significant differences are indicated with asterisks at $P \leq 0.10\left(^{*}\right), P \leq 0.01\left(^{* *}\right)$ and $P \leq 0.001\left(^{* * *}\right.$ ) (least-squares means comparisons).

detected among treatments $(\mathrm{F}=0.24 ; \mathrm{df}=4,25 ; P=0.915)$. Based on the difference between the highest and lowest egg removal rates, variation among insecticides was only 12.5, $17.3,9.7$ and $8.5 \%$ at one, two, three and four WAT.

\section{Seasonal variation in the impact of imidacloprid (experiment 3)}

As in experiment 2, egg removal rates were significantly lower in 2006 than $2007(\mathrm{~F}=19.6 ; \mathrm{df}=1,143 ; P<0.0001)$. Averaged across the four WAT in 2006, mean two-day removal rates in the untreated check were $45.1 \pm 4.0 \%$ in July, $34.5 \pm 3.7 \%$ in August and $54.7 \pm 3.2 \%$ in September. Corresponding values in 2007 were $67.2 \pm 4.7,59.1 \pm 4.1$ and $53.6 \pm 4.2 \%$.

The effect of imidacloprid on egg removal rates did not vary across month of application as there was no significant month $\times$ treatment interaction in either 2006 or 2007 (table 4). Pooled across WAT in 2006, egg removal in the imidacloprid plots compared to the untreated plots was suppressed 16.0, 7.5 and $28.3 \%$ in July, August and September, respectively. The corresponding values in 2007 were 16.7, 27.4 and 29.5\%.

In contrast, there was a significant effect of treatment, month, WAT and month $\times$ WAT in both 2006 and 2007 (table 4). Unlike the results from experiment 2, egg removal was significantly reduced at one, two, three and four WAT (fig. 2). The only exception was three WAT in 2006. Relative to the untreated check, egg removal rates in the imidacloprid plots were reduced 39.2, 21.4, (-9.8) and 14.6\% across the four WAT in 2006. The corresponding values in 2007 were $39.2,25.8,14.3$ and $17.0 \%$. The change in degree of reduction diverged from the trend revealed in experiment 2 , where the impact of imidacloprid was strongest at two and three WAT and absent at four WAT.

\section{Discussion}

The main objective of this study was to determine if applications of neonicotinoid insecticides influence the rates of predation on Japanese beetle eggs. A difference in
Table 4. Results from a multi-level ANOVA examining the effect of imidacloprid (treatment) on Japanese beetle egg predation with respect to month of application (July, August, September) and week after treatment (WAT: 1, 2, 3, 4) over two years.

\begin{tabular}{llccrr}
\hline Year & \multicolumn{1}{c}{ Source } & $\begin{array}{c}\mathrm{df} \\
\text { Num }\end{array}$ & $\begin{array}{c}\mathrm{df} \\
\text { Den }\end{array}$ & \multicolumn{1}{c}{$F$} & \multicolumn{1}{c}{$P$} \\
& & 1 & 119 & 12.94 & 0.0005 \\
2006 & Treatment & 2 & 119 & 11.65 & $<0.0001$ \\
& Month & 2 & 119 & 2.60 & 0.0786 \\
Treatment $\times$ month & 3 & 119 & 9.07 & $<0.0001$ \\
WAT & 3 & 119 & 3.84 & 0.0115 \\
Treatment $\times$ WAT & 6 & 119 & 7.13 & $<0.0001$ \\
Month $\times$ WAT & 6 & 119 & 2.27 & 0.0412 \\
Treatment $\times$ month $\times$ WAT & 1 & 119 & 33.14 & $<0.0001$ \\
Treatment & 2 & 119 & 13.92 & $<0.0001$ \\
Month & 2 & 119 & 0.40 & 0.6684 \\
Treatment $\times$ month & 3 & 119 & 6.45 & 0.0004 \\
WAT & 3 & 119 & 1.79 & 0.1524 \\
Treatment $\times$ WAT & 6 & 119 & 13.87 & $<0.0001$ \\
Month $\times$ WAT & 6 & 119 & 0.73 & 0.6233 \\
Treatment $\times$ month $\times$ WAT & & & & & \\
\hline
\end{tabular}

predation activity was expected because imidacloprid applications were recently documented as reducing the abundance of certain nontarget beneficial fauna in turfgrass (Peck, 2009a,b) and because white grub eggs are included in the diet of generalist predators. As predicted, under the conditions of this study, the rate of egg removal decreased after a single neonicotinoid application, and the effect persisted for as long as 3-4 weeks. The results also matched predictions that the detrimental effects on predation would not vary with neonicotinoid chemistry nor with month of application.

\section{Magnitude and persistence of impacts}

Results confirm the idea that the natural regulation of pest populations is meaningful to the suppression of pest outbreaks and, thereby, favors the sustainability of turf habitats (Potter, 1993). In untreated plots, the natural rates of 
two-day egg removal varied from $41-78 \%$ when sampling dates were pooled across the five studies conducted from 2005 to 2007. Those rates were similar to other turfgrass studies that used implanted grub eggs in stands of Kentucky bluegrass. López \& Potter (2000) measured 45-55\% removal over $12 \mathrm{~h}$ of exposure on golf course roughs (mowing height $5 \mathrm{~cm}$ ) and $2-38 \%$ on fairways (mowing height $3 \mathrm{~cm}$ ). Kunkel et al. (1999) measured 21-48\% removal over three days, and Terry et al. (1993) measured 35-75\% removal over two days in experimental lawns (mowing height $5 \mathrm{~cm}$ ). After an imidacloprid application, however, declines in egg removal rates were detected in all five studies conducted from 2005 to 2007, ranging as high as 28.3-76.1\%. Egg removal was disrupted as soon as one WAT and was expressed for at least four WAT; and, because sampling was discontinued at four WAT, it is possible disruption could have lasted longer. There is a degree of incongruence in the long residual of neonicotinoids and the instances when the disruptive effect was brief, such as in 2005 when egg predation rates recovered in imidacloprid plots between ten and 20 DAT. This is more consistent with a short-term acute response mediated through some form of direct versus systemic exposure. The mobility of generalist predators, such as ants, ground beetles and rove beetles, means they could respond relatively rapidly to acute insecticidal effects through dispersal between treated and untreated areas. While the magnitude of disruption on egg removal rates measured here is probably meaningful for the regulation of pest populations, ascertaining the practical relevance for turf management will depend on future studies.

\section{Seasonal variation}

No significant variation was detected in the effect on egg removal when applications were made at different times in the season, i.e. from July to September. Although recommended for application during the period of oviposition, imidacloprid has a fairly forgiving window of treatment because of its long residual. In the Northeast, it can be effective when applied from early June to mid August, but some individual studies do show efficacy as a Japanese beetle curative as late as early September (e.g. Heller \& Kline, 2005; Swier \& Rollins, 2006). Regardless, due to the long residual of neonicotinoids, there is the possibility of modifying the timing of applications in order to promote control efficacy as well as to mitigate detrimental outcomes such as nontarget effects. In their study on the impact of imidacloprid to a specialist parasitoid, Rogers \& Potter (2003) showed that early preventive treatments significantly interfered with the activities of Tiphia vernalis (Hymenoptera: Tiphiidae), but late preventive treatments did not. A group of generalist predators, not individual species of specialist enemies, are the likely agent of egg removal in our studies (Terry et al., 1993; Kunkel et al., 1999; López \& Potter, 2000). If predator abundance and activity varies relatively little over the application season, it could explain the lack of a seasonal effect, and make it less likely that adjustments in the timing of neonicotinoid applications could mitigate the disruptive effects on egg predation.

\section{Neonicotinoid variation}

No meaningful or consistent variation was detected among the impacts of clothianidin, dinotefuran, imidacloprid and thiamethoxam on egg removal. Across WAT and years, variation among insecticides only ranged from 7.0 to $24.4 \%$. A treatment effect was detected as early as one WAT for dinotefuran, imidacloprid and thiamethoxam in 2007, but not until two WAT for all other trials. A treatment effect only persisted through one WAT for imidacloprid in 2007 and two WAT for clothianidin and dinotefuran in 2006, but through three WAT for all other trials. Beyond physical and toxicological attributes of their chemical class, functional similarities among these products include systemicity and relatively long residual (Tomizawa \& Casida, 2003; Jeschke \& Nauen, 2008). These neonicotinoids, however, do vary in attributes like translocation and translaminar activity (Buchholz \& Nauen, 2001; Elbert et al., 1998). Based on our results, differences among those chemistries may have no meaningful relevance for the degree to which pest suppression is disrupted. Whether that translates to similar population level impacts on the nontarget arthropods that contribute to egg removal is unclear. Oliver et al. (2005) revealed a negative effect of soil-incorporated thiamethoxam, but not imidacloprid, on Tiphia parasitoid development. Although scarce, studies from other agroecosystems reveal differences in the impacts of neonicotinoid chemistries on the abundance of nontarget arthropods (Kilpatrick et al., 2005).

\section{Identity of egg predators}

This study did not identify which nontarget taxa contributed to the removal of Japanese beetle eggs. Formicidae (ants) and the beetle families Carabidae, Cicindelidae, Histeridae and Staphylinidae are confirmed predators of grub eggs (Terry et al., 1993; López \& Potter, 2000). One study on home lawns identified 17 species of carabids alone (Rochefort et al., 2006), indicating the potential diversity of natural enemies in turf systems. Our results did reveal some negative impacts on Carabidae and Formicidae, but the overall evidence was mixed and inconclusive. Based on pitfall sampling, in imidacloprid plots the abundance-activity of Carabidae was higher at ten DAT but lower at 20 DAT. In contrast, non-myrmicine Formicidae was lower at ten DAT, but myrmicine and non-myrmicine Formicidae were higher at 20 DAT. Egg scavenging might occur in two other groups negatively impacted by imidacloprid. Porcellionidae (sowbugs) was lower at ten DAT, while Orthoptera (largely Gryllidae) was lower at both DAT. Based on soil core extractions, population effects were consistently negative among the only group of affected potential predators, Formicidae. Abundance was lower for total ant adults and Myrmicinae at both DAT and for Lasius spp. at ten DAT. Thysanoptera might also contribute to egg removal as scavengers or facultative predators; their abundance was lower at ten DAT.

Previous work documented a similar density of soilactive arthropods extracted from soil cores (7616 to 25,826 individuals $\mathrm{m}^{-2}$ ) but did not reveal any impacts of single imidacloprid applications (Peck, 2009a). In that study, however, a relatively long post-application sampling interval (2-3 wk) could have obscured any response. Over the longterm, six consecutive seasons of imidacloprid applications led to a significant reduction in two largely predaceous beetle families (Carabidae and Staphylinidae) but not in two largely phytophagous families (Chrysomelidae and Curculionidae) (Peck, 2009b). Therefore, it was proposed that an imidacloprid-mediated decrease in Collembola populations led to a decrease in predatory beetle populations through the removal of food resources. While the results presented here 
do not confirm a definitive imidacloprid effect on the Carabidae, they do indicate an effect on the Collembola. As measured through soil cores extractions, the abundance of Onychiurus, Proisotoma, Pseudosinella and Symphypleona was 3.3-, 28.0-, 1.4- and 5.0-fold lower at ten DAT. Abundance recovered by $20 \mathrm{DAT}$, with the exception of Proisotoma 9.3-fold lower.

The specific identity of predators remains a black box and an obvious subject of future research, as is how a neonicotinoid effect is channeled through them to impact egg removal rates. It is likely that a suite of generalist natural enemies will have to be addressed. The fact that removal rates did not vary across season is consistent with activity from a complex of generalist predators that would be less variable through time, rather than from a few individual species.

\section{Post-application irrigation}

Our study was not designed to establish how the timing, amount and variation in post-application rainfall influenced the outcome of our results. Given the overall decline in precipitation from 2006 to 2007, however, it was feasible to assess whether differences in treatment effects may have been attributable to differences in post-application precipitation (table 1). In experiment 3, the week after application in the July trials the total rainfall declined considerably from $2006(57.5 \mathrm{~mm})$ to $2007(2.5 \mathrm{~mm})$; however, the suppressive effect of imidacloprid on egg predation was nearly identical (16.0 and $16.7 \%$, respectively). In contrast, a similar decline in precipitation from 2006 (18.0) to $2007(0.5 \mathrm{~mm})$ in the August trials was associated with a higher degree of variation in egg predation suppression (7.5 and $27.5 \%$, respectively). In experiment 2 (fig. 1), post-application rainfall also declined from $2006(18.6 \mathrm{~mm})$ to 2007 (2.5 mm); but, again, there was no discernible trend that linked variation in rainfall data with the detection or magnitude of treatment effects on egg predation rates.

\section{Implications}

We recommend that future studies examine not only how application timing and irrigation affect insecticide performance, but how they might be manipulated to mitigate the negative consequences posed by long-residual neonicotinoid insecticides on the abundance and function of nontarget arthropods. When insecticides target soil insects in turf, a general recommendation is to follow with irrigation so material moves from the foliage to the target zone before any degradation due to wind and sun exposure (Potter, 1998). As post-application irrigation is linked to improved performance against white grubs for at least imidacloprid, irrigation might also influence the scope of nontarget effects. Kunkel et al. (2001), for instance, showed that post-application irrigation reduced the deleterious behavioral effects of granular imidacloprid on surface-active generalist predators because of decreased insecticide exposure. Under the conditions of our study, post-application irrigation was uncontrolled as it relied on natural precipitation. Similar application scenarios may be widespread in the northeast US. On the labels of all five products evaluated in our study, recommendations on post-application irrigation are variably inexplicit, which may contribute to poor adoption. Moreover, this practice may not even be achievable under many circumstances given the prominence of non-irrigated turf systems. In New York state, for instance, $85 \%\left(9740 \mathrm{~km}^{2}\right)$ of residential lawns are non-irrigated, as well as $62-63 \%$ of turf on golf courses and sod farms and $81-87 \%$ on park and school grounds (NASS, 2004).

Neonicotinoids (at least imidacloprid) are recommended for application at the time of Japanese beetle oviposition, which puts their unintended effects (disruption of egg predation) in direct conflict with their intended effects (mortality of neonate white grubs). We speculate on one scenario whereby the role of natural enemies could be capitalized within a management program that relies on intervention with long-residual insecticides. Delaying imidacloprid applications means more chances to scout, assess thresholds and spot-treat smaller areas. The concomitant decline in efficacy with increasing white grub instar could be buffered by conservation of predation on early life stages. Early application, on the contrary, may not be a promising approach. While imidacloprid can be highly effective when applied up to eight weeks before oviposition (e.g. Heller \& Kline, 2007), the marginal increase due to predation might be inconsequential.

Under scenarios that include a diverse local fauna and low pest pressure, it might be reasonable to expect that the activities of natural enemies could supplant much of the reliance on preventive insecticides. Using insecticides in a sound and effective manner, consistent with IPM principles, is a priority for environmental stewardship in turf. It will conserve the role of beneficials, reduce groundwater contamination, proactively assuage public concerns over usage, and safeguard the long-term use of neonicotinoids as effective and low risk alternatives for insect pest management. Refining our understanding of the balance between the intended and unintended consequences of preventive insecticides will enhance opportunities for pest management practitioners to harness the benefits of natural pest control.

\section{Acknowledgements}

We thank A. Corichi, E. Jennings, A. Mazo, A. Morales, K. Nelson and C. Ospina for assistance in the laboratory and field. For agronomic advice and support, we thank B. Arehart, S. Gordner, F. Rossi and M. Thurne. Ant species were initially identified by $\mathrm{C}$. Klass. Three anonymous reviewers and G. Loeb made comments that greatly improved the manuscript.

\section{References}

Abbott, V.A., Nadeau, J.L., Higo, H.A. \& Winston, M.L. (2008) Lethal and sublethal effects of imidacloprid on Osmia lignaria and clothianidin on Megachile rotundata (Hymenoptera: Megachilidae). Journal of Economic Entomology 101, 784-796.

Beard, J.B. \& Green, R.L. (1994) The role of turfgrasses in environmental protection and their benefits to humans. Journal of Environmental Quality 23, 452-460.

Buchholz, A. \& Nauen, R. (2001) Translocation and translaminar bioavailability of two neonicotinoid insecticides after foliar applications to cabbage and cotton. Pest Management Science 58, 10-16.

Chauzat, M.P., Faucon, J.P., Martel, A.C., Lachaize, J., Cougoule, N. \& Aubert, M. (2006) A survey of pesticide 
residues in pollen loads collected by honey bees in France. Journal of Economic Entomology 99, 253-262.

Cockfield, S.D. \& Potter, D.A. (1983) Short-term effects of insecticidal applications on predaceous arthropods and oribatid mites in Kentucky bluegrass turf. Environmental Entomology 12, 1260-1264.

Dively, G. (2005) Impact of transgenic VIP3A x Cry1Ab lepidopteran-resistant field corn on the nontarget arthropod community. Environmental Entomology 34, 1267-1291.

Elbert, A., Nauen, R. \& Leicht, W. (1998) Imidacloprid, a novel chloronicotinyl insecticide: biological activity and agricultural importance. pp. 50-73 in Ishaaya, I. \& Degheele, D. (Eds) Insecticides with Novel Modes of Action: Mechanism and Application. Berlin, Germany, Springer.

Halm, M.P., Rortais, A., Arnold, G., Tasei, J.N. \& Rault, S. (2006) New risk assessment approach for systemic insecticides: the case of honey bees and imidacloprid (Gaucho). Environmental Science E Technology 40, 2448-2454.

Heller, P.R. \& Kline, D. (2005) Curative applications of Provaunt and Merit formulations to suppress scarab white grubs, 2004. Arthropod Management Tests 30, G32.

Heller, P.R. \& Kline, D. (2007) Mid-April applications of DPXE2Y45 and Merit to preventively suppress scarab white grubs, 2006. Arthropod Management Tests 32, G13.

Jeschke, P. \& Nauen, R. (2008) Neonicotinoids - from zero to hero in insecticide chemistry. Pest Management Science 64, 1084-1098.

Kilpatrick, A.L., Hagerty, A.M., Turnipseed, S.G., Sullivan, M.J. \& Bridges Jr., W.C. (2005) Activity of selected neonicotinoids and dicrotophos on nontarget arthropods in cotton: implications in insect management. Journal of Economic Entomology 98, 814-820.

Kunkel, B.A., Held, D.W. \& Potter, D.A. (1999) Impact of halofenozide, imidacloprid, and bendiocarb on beneficial invertebrates and predatory activity in turfgrass. Journal of Economic Entomology 92, 922-930.

Kunkel, B.A., Held, D.W. \& Potter, D.A. (2001) Lethal and sublethal effects of bendiocarb, halofenozide, and imidacloprid on Harpalus pennsylvanicus (Coleoptera: Carabidae) following different modes of exposure in turfgrass. Journal of Economic Entomology 94, 60-69.

López, R. \& Potter, D.A. (2000) Ant predation on eggs and larvae of the black cutworm (Lepidoptera: Noctuidae) and Japanese beetle (Coleoptera: Scarabaeidae) in turfgrass. Environmental Entomology 29, 116-125.

Maienfisch, P., Angst, M., Brandl, F., Fischer, W., Hofer, D., Kayser, H., Kobel, W., Rindlisbacher, A., Senn, R., Steinemann, A. \& Widmer, H. (2001) Chemistry and biology of thiamethoxam: a second generation neonicotinoid. Pest Management Science 57, 906-913.

Marvier, M., McCreedy, C., Regetz, J. \& Kareiva, P. (2007) A meta-analysis of effects of $B t$ cotton and maize on nontarget invertebrates. Science 316, 1475-1477.

Naranjo, S.E. (2005a) Long-term assessment of the effects of transgenic Bt cotton on the abundance of non-target arthropod natural enemies. Environmental Entomology 34, 1193-1210.

Naranjo, S.E. (2005b) Long-term assessment of the effects of transgenic $B t$ cotton on the function of the natural enemy community. Environmental Entomology 34, 1211-1223.

NASS (New York Agricultural Statistics Service) (2004) 2003 New York Turfgrass Survey. Albany, NY, USA, NASS.

NTF (National Turfgrass Federation) (2003) National Turfgrass Research Initiative: Enhancing America's beauty, protecting America's natural resources and ensuring the health and safety of all America. Beltsville, MD, USA, NTF.

Oliver, J.B., Mannion, C.M., Klein, M.G., Moyseenko, J.J. \& Bishop, B. (2005) Effect of insecticides on Tiphia vernalis (Hymenoptera: Tiphiidae) oviposition and survival of progeny to cocoon stage when parasitizing Popillia japonica (Coleoptera: Scarabaeidae) larvae. Journal of Economic Entomology 98, 694-703.

Peck, D.C. (2009a) Comparative impacts of white grub (Coleoptera: Scarabaeidae) control products on the abundance of nontarget soil-active arthropods in turfgrass. Pedobiologia 52, 287-299.

Peck, D.C. (2009b) Long term effects of imidacloprid on the abundance of surface- and soil-active nontarget fauna in turf. Agricultural and Forest Entomology 11, 405-419.

Potter, D.A. (1993) Pesticide and fertilizer effects on beneficial invertebrates and consequences for thatch degradation and pest outbreaks in turfgrass. pp. 331-343 in Racke, K.D. \& Leslie, A.R. (Eds) Pesticides in Urban Environments: Fate and Significance. ACS Symposium Series 522. Washington, DC, USA, American Chemical Society.

Potter, D.A. (1994) Effects of pesticides on beneficial invertebrates in turf. pp. 59-70 in Leslie, A.R. (Ed.) Handbook of Integrated Pest Management for Turf and Ornamentals. Boca Raton, FL, USA, Lewis Publishers.

Potter, D.A. (1998) Destructive turfgrass insects: biology, diagnosis, and control. Chelsea, MI, USA, Ann Arbor Press.

Rochefort, S., Shetlar, D.J. \& Brodeur, J. (2006) Ground beetle assemblages (Coleoptera: Carabidae) and their seasonal abundance in cool season turfgrass lawns of Quebec. Environmental Entomology 35, 1508-1514.

Rogers, M. \& Potter, D.A. (2003) Effects of spring imidacloprid application for white grub control on parasitism of Japanese beetle (Coleoptera: Scarabaeidae) by Tiphia vernalis (Hymenoptera: Tiphiidae). Journal of Economic Entomology 96, 1412-1419.

SAS Institute (2003) JMP: The Statistical Discovery Software. Version 5. Cary, NC, USA, SAS Institute.

Smith, S.F. \& Krischik, V.A. (1999) Effects of systemic imidacloprid on Coleomegilla maculata (Coleoptera: Coccinellidae). Environmental Entomology 28, 1189-1195.

Swier, S.R. \& Rollins, A. (2006) Comparisons of various granular consumer formulations for late-season curative control of Japanese beetle, 2005. Arthropod Management Tests 31, G25.

Terry, L.E. \& Potter, D.A. (1987) Impact of a high-maintenance lawn-care program on nontarget invertebrates in Kentucky bluegrass turf. Environmental Entomology 16, 100-105.

Terry, L.E., Potter, D.A. \& Spicer, P.G. (1993) Insecticides affect predatory arthropods and predation on Japanese beetle (Coleoptera: Scarabaeidae) eggs and fall armyworm (Lepidoptera: Noctuidae) pupae in turfgrass. Journal of Economic Entomology 86, 871-878.

Tomizawa, M. \& Casida, J. (2003) Selective toxicity of neonicotinoids attributable to specificity of insect and mammalian nicotinic receptors. Annual Review of Entomology 48, 339-364.

Vavrek, R.C. \& Niemczyk, H.D. (1990) Effect of isofenphos on nontarget invertebrates in turfgrass. Environmental Entomology 19, 1572-1577.

Wakita, T., Kinoshita, K., Yamada, E., Yasui, N., Kawahara, N., Naoi, A., Nakaya, M., Ebihara, K., Matsuno, H. \& Kodaka, K. (2003) The discovery of dinotefuran: a novel neonicotinoid. Pest Management Science 59, 1016-1022. 
Wolfenbarger, L.L., Naranjo, S.E., Lundgren, J.E., Bitzer, R.J. \& Watrud, L.S. (2008) Bt crop effects on functional guilds of non-target arthropods: a meta analysis. PloS ONE 3, e2118. doi:10.1371/journal.pone.0002118.
Zenger, J.T. \& Gibb, T.J. (2001) Impact of four insecticides on Japanese beetle (Coleoptera: Scarabaeidae) egg predators and white grubs in turfgrass. Journal of Economic Entomology 94, 145-149. 